\title{
Development and Evaluation of a Pilot Prototype Automated Online Sampling System
}

by

M. J. Whitaker

Westinghouse Savannah River Company

Savannah River Site

Aiken, South Carolina 29808

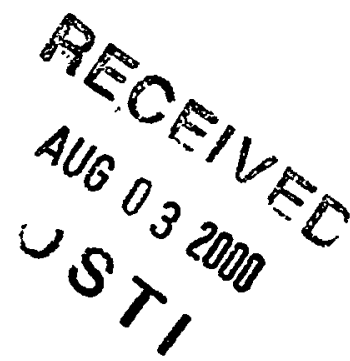

DOE Contract No. DE-AC09-96SR18500

This paper was prepared in connection with work done under the above contract number with the U.S.

Department of Energy. By acceptance of this paper, the publisher and/or recipient acknowledges the U.S.

Government's right to retain a nonexclusive, royalty-free license in and to any copyright covering this paper, along with the right to reproduce and to authorize others to reproduce all or part of the copyrighted paper. 


\section{DISCLAIMER}

This report was prepared as an account of work sponsored by an agency of the United States Government. Neither the United States Government nor any agency thereof, nor any of their employees, makes any warranty, express or implied, or assumes any legal liability or responsibility for the accuracy, completeness, or usefulness of any information, apparatus, product or process disclosed, or represents that its use would not infringe privately owned rights. Reference herein to any specific commercial product, process or service by trade name, trademark, manufacturer, or otherwise does not necessarily constitute or imply its endorsement, recommendation, or favoring by the United States Government or any agency thereof. The views and opinions of authors expressed herein do not necessarily state or reflect those of the United States Government or any agency thereof.

This report has been reproduced directly from the best available copy.

Available for sale to the public, in paper, from: U.S. Department of Commerce, National Technical Information Service, 5285 Port Royal Road, Springfield, VA 22161, phone: (800) 553-6847,

fax: (703) 605-6900

email: orders@ntis.fedworld.gov

online ordering: http://www.ntis.gov/ordering.htm

Available electronically at http://www.doe.gov/bridge

Available for a processing fee to U.S. Department of Energy and its contractors, in paper, from:

U.S. Department of Energy, Office of Scientific and Technical Information, P.O. Box 62,

Oak Ridge, TN 37831-0062,

phone: (865)576-8401,

fax: (865)576-5728

email : reportsaadonis.osti.gov 


\section{DISCLAIMER}

\section{Portions of this document may be illegible in electronic image products. Images are produced from the best available original document.}


BNF-003-98-0293

June 29,2000

\title{
Development and Evaluation of a Pilot Prototype Automated Online Sampling System for the BNFL-Hanford Technetium Monitoring Program
}

\author{
Michael J. Whitaker, Frank M. Pennebaker and Brian B. Anderson \\ Westinghouse Savannah River Company, Building 773A, Aiken, SC 29808
}

\section{DISCLAIMER NOTICE}

This report was prepared by Westinghouse Savannah River Company, Inc. (WSRC) on behalf of the U.S. Department of Energy (DOE), as an account of work sponsored by BNFL, Inc. Neither WSRC, DOE, the U.S. Government, or any person acting on their behalf makes any warranty, express or implied, or assumes any legal liability or responsibility for the accuracy, completeness, or usefulness of any information, apparatus, product, or process disclosed, or represents that its use would not infringe privately owned rights. Reference herein to any specific commercial product, process, or service by trade name, trademark, manufacturer, or otherwise, does not necessarily constitute or imply its endorsement, recommendation, or favoring by WSRC, DOE, or the U.S. Government. The views and opinions of authors expressed herein do not necessarily state or reflect those of WSRC, DOE, or the U.S. Government.

Savannah River Technology Center Westinghouse Savannah River Company Aiken, SC 29808 
BNF-003-98-0293

June 29, 2000

Page 2 of 15

\section{Approvals}

2. Novtaber

$7-20-00$

Michael J. Whitaker

Date

$\ln _{4} d x d$

$7-20-0$

Frank M: Pennebaker

Date

Onson

Brian B. Anderson

$7-20-00$

Date

Detopentsu

C. Wayme Jénkins

Level 3 Manager - Analytical Development Section

$2 / 20 / 2000$

Date 
BNF-003-98-0293

June 29,2000

Page 3 of 15

\section{Executive Summary}

An automated online sampling system (AOSS) has been developed for the BNFL-Hanford Technetium Monitoring Program. The system was designed to be flexible and allows for the collection and delivery of samples to a variety of detection devices that may be used. The AOSS was constructed as two individual and separate components, a wet component and a controller component. The wet component consists or three pumps and four valves. It was designed to be compact to reside on a bench top for nontoxic or non-radiological solution or in a chemical or a radiological hood or glove box to accommodate toxic or radioactive solutions. The hardware and software for the Technetium Monitoring AOSS was designed to be flexible and versatile, yet simple to operate. Touch screen technology allows for a large variety of options for adjustments and parameter settings to analytical routines.

A 12 hour experiment was performed using a fiber optic coupled spectrometer system to evaluate the AOSS long term capability and functionality. A simple sampler control program was written to analyze 12 simulated samples, 4 blanks and 4 standards in the 12-hour period. The AOSS software and hardware functioned without a flaw.

Overall, the sampling system worked well coupled to the ICP-ES. Relative precision was approximately $2 \%$ over 8 hours for $10 \mathrm{mg} / \mathrm{L}$ Re solutions. Precision was degraded slightly in switching to envelope $\mathrm{A}$ spiked with Re.

\section{Background}

Typically an automated online sampling system (AOSS) is a system that automatically retrieves a known volume of sample from a process stream or some other originating source. The collected sample, known as a sample slug, is then delivered to a device to measure the concentration of the analyte of interest or a chemical characteristic such as the $\mathrm{pH}$ of the sample. A prescribed sequence of sampling is generally designed into an AOSS so the system can repetitively collect samples at precise increments over time. Often it is necessary to design the system to perform a physical and/or chemical preparation on the sample before the analyte of interest can be detected. Sample preparation steps may include: filtration or extraction of the sample; the addition of an acid or base to adjust the $\mathrm{pH}$; addition of a reagent to perform a chemical reaction; the addition of deionized water to dilute the sample; or a combination of some or all of these types of sample preparation techniques. Hardware and software flexibility is often designed into an automated online sampling system so adjustments to analytical routines may be quickly and easily made.

The scope of work for the BNEL-Hanford Technetium Monitoring Program included evaluation of two emission spectroscopy techniques, Individually-Coupled Plasma (ICP) and Direct-Coupled Plasma (DCP), investigation of beta scintillation methodology, and the development and evaluation of an automated sampling system to collect, perform sample preparations online if required and then deliver the sample to a measuring/monitoring device. This document will report on the development and evaluation of the automated online sampling system. A portion of the evaluation described here will include the use of the automated online sampling system with the ICP-ES. 


\title{
Automated Online Sampling System (AOSS) Development
}

\author{
Sequence of Development
}

06/02/99 - Initial trip to Sampling Systems facility in Old Ocean, Texas to evaluate capabilities. 06/14/99 - Statement of work and purchase requisition (\#6A3860) submitted to purchasing. 07/26/99 - Technical evaluation of quote from Sampling Systems.

08/11/99 - AOSS contract awarded to Sampling Systems.

08/17/99 - Second trip to Sampling Systems to discuss technical details for construction of hardware and development of software for AOSS.

11/08/99 - Third trip to Sampling Systems to evaluate progress.

01/17/00 - Four trip to Sampling Systems to do final evaluation.

01/27/00 - AOSS shipped.

02/07/00 - SRTC received AOSS.

It was determined early in the development process that the AOSS would most likely be used with a variety of detection devices. Thus, the AOSS would require flexible hardware and software qualities to accommodate the needs of the different measuring/monitoring instruments to be evaluated and utilized over the course of the BNFL-Hanford Technetium Monitoring Program. In response to this need SRTC designed a pilot prototype automated online sampling system with capabilities to accommodate a wide range of online sample manipulations. Consideration of project timeframe, cost, and milestones led us to procure an off-site commercial vender to assist with hardware and software development under the direction and oversight of an SRTC scientist. After thorough investigation of facilities and evaluation of technical capabilities, Sampling Systems of Old Ocean, Texas was selected as the off-site commercial vendor to construct the AOSS. It should also be noted there was a positive work history experience with this company on a previous project when it built a field deployable tritium analysis system for SRTC.

The hardware and software for the Technetium Monitoring AOSS was designed to be flexible and versatile, yet simple to operate. Touch screen technology allows a wide variety of options to be set or adjusted: pump speed flow rates; discrete sample volumes; valve selection and position; option to add or remove reagents and standards; sampling and analysis rate; stop-flow; and much more. The design of the system also enables the use of numerous online sample preparation techniques, including filtration, extraction, ion exchange, redox and dilution, to mention a few.

The AOSS was constructed as two individual and separate components: a wet component and a controller component. A picture of the two components is shown in Figure 1 and a flow diagram of the complete AOSS is illustrated in Figure 2. The system's wet component manipulates solutions through sixteenth inch stainless steel tubing by three pumps and four valves. A picture and schematic of the wet component are shown in Figures 3 and 4, respectively. The wet component was designed to be compact to reside on a bench top for non-toxic or non-radiological solutions or in a chemical or a radiological hood or glove box to accommodate toxic or radioactive solutions. Following the diagram in Figure 2 the flow of sample through the AOSS begins at valve \#1, a four-position selector valve with selection options between a wash solution, blank, standard, or process stream. Once the sample type has been selected the sample is then directed to pump 1x. Valve \#2 allows for the addition to the sample of a 
wash solution or reagent (acid, base, etc.) through pump $8 \mathrm{x}$, automatically diluting the sample by a factor of nine. Valve \#3 then directs the diluted sample to either flow to waste or a discrete volume of the sample to flow to the mixing chamber. When the sample flows to the mixing chamber, valve \#4 is open to the pump designated as $1.5 \mathrm{mU} / \mathrm{min}$ and the diluted sample is pumped to the analyzer and monitored. Otherwise, when valve \#3 directs the diluted sample to waste, valve \#4 is closed to the mixing chamber and open to an internal standard to ensure a constant flow of solution to the analyzer.

With the possibility and likelihood of the second component of the AOSS being exposed to toxic and/or radioactive solutions with the BNFL-Hanford Monitoring Program, a number of safety issues were considered and incorporated into the system. The most obvious was the design of the AOSS itself with two separate components. The wet component was designed to be contained in a hood or glove box. A less obvious safety element, but certainly important; was the design of the mixing chamber itself, as illustrated in a close-up picture of the mixing chamber in Figure 5 and in schematic form in Figure 4. A significant safety feature designed into the AOSS was the mixing cell pressure relief vent. It was determined early on when acid was added to the BNFL-Hanford residue there was the evolution of . carbon dioxide. This type of evolution of gas in the AOSS could cause back pressure in the system and possibly cause leakage. To prevent back pressure and possible leakage in the system a vent tube was designed into the mixing chamber. Another safety feature incorporated into the mixing chamber was the addition of photoelectric sensors to control upper and lower solution limits. These sensors are illustrated as numbers 4 and 5 in Figure 4. They serve to the control liquid level in the mixing chamber. The upper sensor limits the amount of liquid in the cell by shutting off the pumps when it is activated. This prevents overflow and leakage of solution in the mixing cell. The lower sensor interacts with the system controller and ensures a minimum level is achieved in the mixing chamber to prevent pump damage.

The second component of the AOSS is the system controller. A picture and schematic of the controlling component are shown in Figures 6 and 7, respectively. The second component was designed to reside on a bench top or a specially constructed pedestal type stand outside the hood, glove box, or contained area and remotely control the wet component unit. The controlling unit of the AOSS is composed of two stepper motor controllers for the three pumps; a power supply for the total sampling system; three Direct Logic 05 programmable logic controllers (PLC) to control valve positions and switching and pump on and off control; a touch screen monitor;and a notebook computer. The touch screen monitor allows the operator to start and stop the AOSS, as well as, set a wide variety of parameters that control various functions of the valves and pumps effecting flow rates, sample size, wash volumes, etc. The notebook computer is equipped with a software application that one can easily develop sophisticated programs to download into the system to operate the AOSS.

The Sampler Control Program Editor (SCPE) is the application used to create, modify and download Sampler Control Programs (SCPs) to the PLCs to operate the AOSS. Each SCP consist of an identification number, a program repeat specifier, and up to 60 program steps. Each program step consist of a cycle repeat value and type. The cycle repeat value may denote an actual repeat value (time or minutes) or other useful information, depending upon the cycle type.

The following table lists the cycle types available and their associated repeat value meanings. 
BNF-003-98-0293

June 29,2000

Page 6 of 15

Table 1 - Cycle Types

\begin{tabular}{|c|c|}
\hline Cycle Type Description & Repeat Value Meaning \\
\hline Flush - Wash/Wash & Valve $1 \&$ Valve 2 Position - 11 \\
\hline Flush - Wash/Acid & Valve 1 \& Valve 2 Position - 12 \\
\hline Flush - Blank/Wash & Valve $1 \&$ Valve 2 Position -21 \\
\hline Flush - Blank/Acid & Valve $1 \&$ Valve 2 Position -22 \\
\hline Flush - Standard/Wash & Valve $1 \&$ Valve 2 Position -31 \\
\hline Flush - Standard/Acid & Valve 1 \& Valve 2 Position - 32 \\
\hline Flush-Process/Wash & Valve 1 \& Valve 2 Position -41 \\
\hline Flush - Process/Acid & Valve 1 \& Valve 2 Position - 42 \\
\hline Analyze & Times to repeat slug volume \\
\hline Internal Standard & Minutes to pump Internal Standard \\
\hline Delay & Minutes to delay without pumping \\
\hline Start Group & Times to repeat the program group \\
\hline End Group & End a program group, always 0 \\
\hline
\end{tabular}

Flush cycles define periods in a particular SCP where pumps 1 and 2 pump a designated volume of solution to waste to adequately flush liquid residue from a previous sample to eliminate cross contamination from one sample to another. A flush cycle will pump one flush volume to waste. While pump 1 and 2 flush the system, an internal standard is pumped to the analyzer by pump 3 at a designated flush rate.

Table 2 is an illustration of a simple SCP.

Table 2 - SCP Example 1

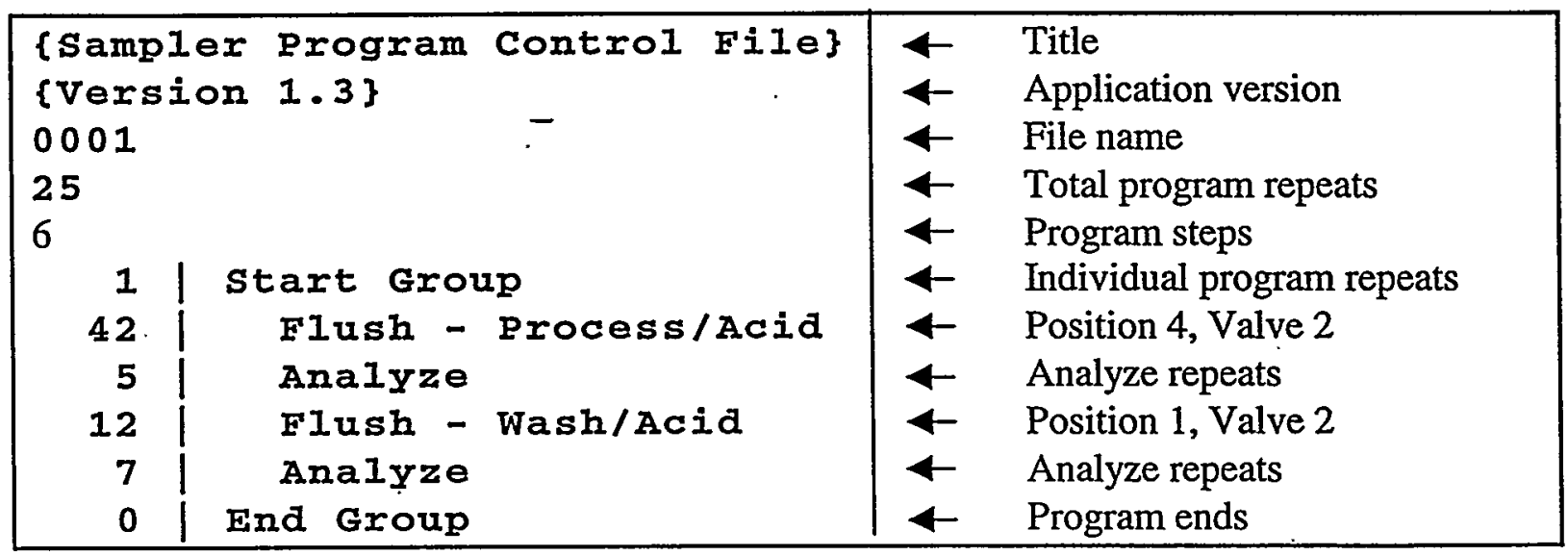


BNF-003-98-0293

June $2 \dot{9}, 2000$

Page 7 of 15

Table 3 is an illustration of a more complex SCP. Program steps can be arranged into groups, and each group can be given a repeat value, that is to say, a number of times for the steps of a particular group to repeat before continuing on with other steps or groups. Groups can be nested within the SCP to four levels. But in effect, the global program repeat value gives the program designer a fifth level of group repeat.

Table 3 - SCP Example 2

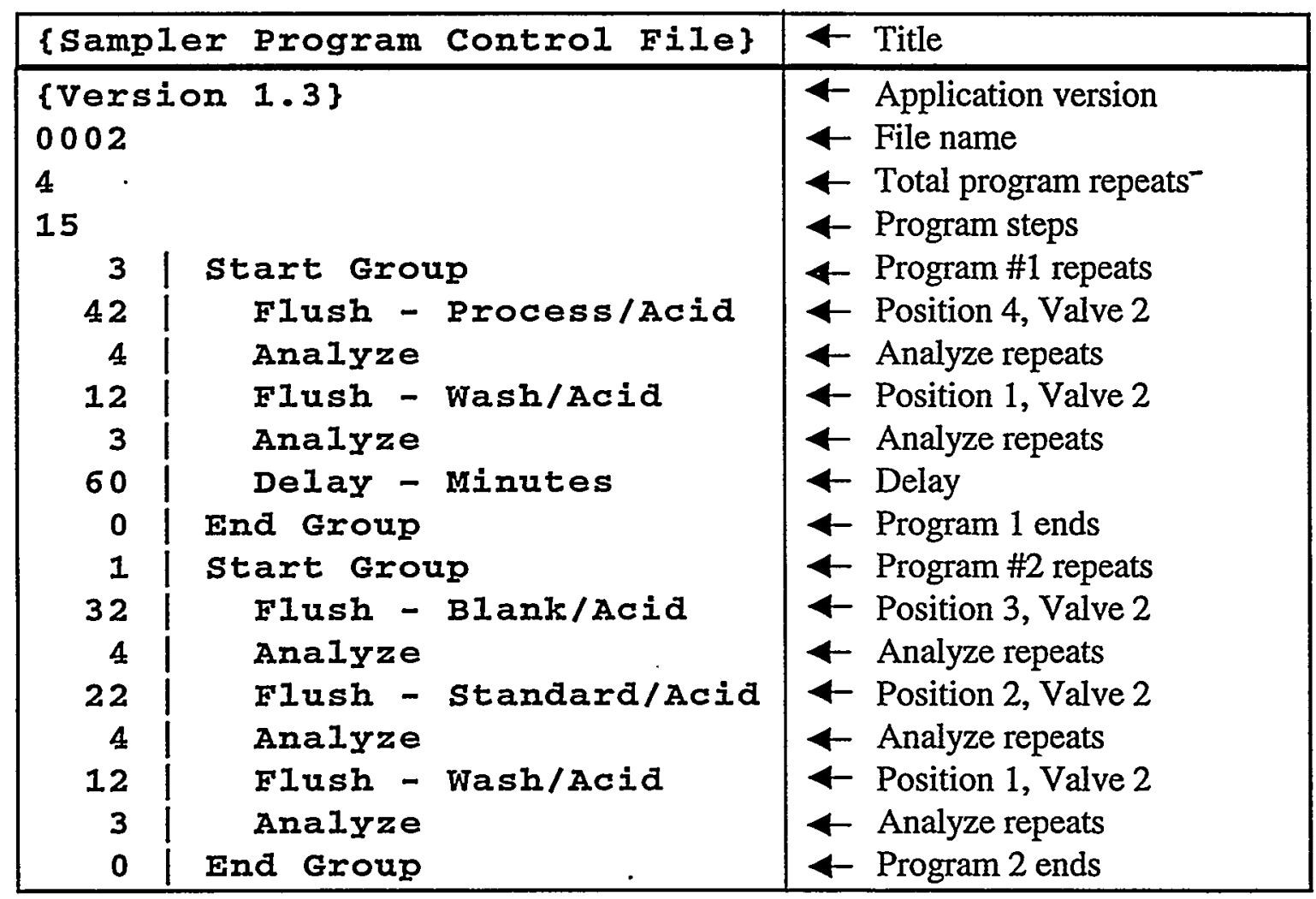

The second SCP illustrated in Table 3 is a good example of nesting a program group within a group. This program was designed for process sample to be analyzed 12 times, once every hour for 12 hours. A blank and standard will be analyzed four times within that 12-hour period. The first group program will cycle through the steps within its program, including the 60 minute delay, three times. After the third cycle of the first group program the second group program will begin to cycle through the steps within its program. When the second group program reaches the end step of its program this will complete the first of four repeats of the SCP. Therefore, the second repeat of this SCP will begin after the second group program reaches the end step of its program and the first group program begins its first cycle again. 
BNF-003-98-0293

June 29,2000

Page 8 of 15

\section{Automated Online Sampling System (AOSS) Evaluation}

\section{Spectrophotometric}

The onsite evaluation of the AOSS was conducted in the non-radiological environment of lab F-193 in building 773-A. Early on two minor software glitches were detected and corrected. The initial evaluation of the AOSS hardware and software to determine various pump speeds, valve selections properties, flow rates, washout times, etc. were preformed using a Spectronic 20 Genesys spectrophotometer. A flow cell was used with different colors of food coloring as surrogate analytes in this evaluation. A sample injection profile is illustrated in Figure 8 and the parameter settings are shown in Table 4. The sampler control program used to generate the sample injection profile is shown in Table 5.

Table 4 - Sample Injection Profile Parameters

\begin{tabular}{|l|l|}
\hline Parameter Deseription & Parameter Setfings \\
\hline Wavelength & $630 \mathrm{~nm}$ \\
\hline Solution & Blue \\
\hline Slug Volume & $1.50 \mathrm{~mL}$ \\
\hline Flush Volume & $45 \mathrm{~mL}$ \\
\hline Analyze Flow Rate & $1.00 \mathrm{~mL} / \mathrm{min}$ \\
\hline Flush Flow Rate & $2.00 \mathrm{~mL} / \mathrm{min}$ \\
\hline
\end{tabular}

Table 5 - Sample Injection Profile SCP

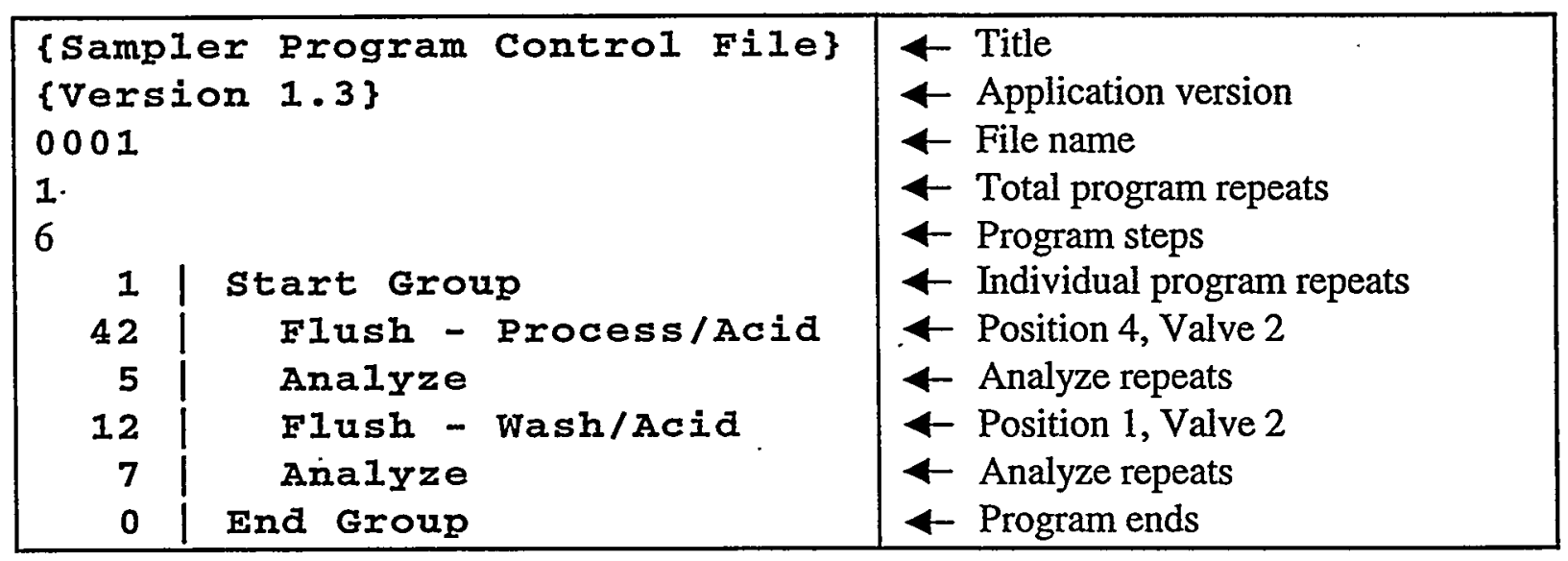

Two peaks are shown in the graph in Figure 8. Note in the SCP demonstrated in Table 5 there are two analyze steps in the program. The first analyze step is for the actual measurement of the sample while the second analyze step in the program is there to flush the mixing chamber with wash solution to prevent cross contamination from one sample to another. 
BNF-003-98-0293

June 29,2000

Page 9 of 15

Before moving the AOSS to the ICP lab, an overnight experiment was developed to evaluate the system's long-term capability and functionality. The results of this overnight experiment are shown in Figure 9, a three-dimensional graph of absorbance, time and wavelength. The experiment was performed using a fiber optic coupled spectrometer system with computer control and data acquisition. The spectrometer was a Ziess MCS-501 spectrograph $(190-1100 \mathrm{~nm})$ with a $2 \mathrm{~nm}$ bandpass and a $0.8 \mathrm{~nm}$ pixel resolution. The system was set up to record absorbance spectra every 10 seconds, after initial reference to deionized water, and was left unattended for the 12 hour acquisition. The SCP illustrated in Table 3 earlier in the document is the program used for this 12 hour evaluation. The AOSS parameter settings for this experiment are listed in Table 6.

Table 6 - Sample Injection Profile Parameters

\begin{tabular}{|l|l|}
\hline Parameter Description & Parameter Settings \\
\hline Wavelength Range & 400 to $750 \mathrm{~nm}$ \\
\hline Solution 1 (process) & Blue \\
\hline Solution 1 (standard) & Red \\
\hline Solution 3 (blank) & Distilled Water \\
\hline Slug Volume & $1.50 \mathrm{~mL}$ \\
\hline Flush Volume & $45 \mathrm{~mL}$ \\
\hline Analyze Flow Rate & $1.00 \mathrm{~mL} / \mathrm{min}$ \\
\hline Flush Flow Rate & $2.00 \mathrm{~mL} / \mathrm{min}$ \\
\hline
\end{tabular}

The AOSS hardware and software functioned without a flaw during the overnight experiment. The SCP was written to analyze 12 process samples, four blanks and four standards over a 12 hour period, as illustrated in the graph in Figure 9.

\section{Automated Online Sampling System (AOSS) Evaluation}

\section{ICP-ES}

\section{Standard and Simulant preparation}

All solutions were prepared using $18 \mathrm{M} \Omega$ deionized water and/or 2-6\% $\mathrm{HNO}_{3}$ diluted from distilled concentrated $\mathrm{HNO}_{3}$ (Optima grade, Fisher Scientific). Rhenium process solution was prepared by diluting $1000 \mathrm{mg} / \mathrm{L}$ Re standard (High Purity Standards, Charleston, SC) with $2 \% \mathrm{HNO}_{3}$ to a final concentration of $10 \mathrm{mg} / \mathrm{L}$. Wash/diluant solutions were prepared at concentrations of $2.0 \mathrm{mg} / \mathrm{L}$ and 0.2 $\mathrm{mg} / \mathrm{L}$ scandium diluted from $1000 \mathrm{mg} / \mathrm{L}$ in $2 \%$ and $6 \% \mathrm{HNO}_{3}$. Envelope A-simulant was prepared based on the agreed upon formulations from BNFL for Hanford tank AN-105 ${ }^{1,2}$. The A-simulant solution was spiked with $10 \mathrm{mg} / \mathrm{L}$ Re from the $1000 \mathrm{mg} / \mathrm{L}$ standard. 
BNF-003-98-0293

June 29, 2000

Page 10 of 15

\section{ICP-ES Instrumentation and Methodology}

A Perkin Elmer Optima 3000 ICP-ES was used with a high solids GemCone nebulizer (Perkin Elmer) to evaluate reproducibility and sample delivery for the AOSS. Plasma conditions are detailed below in Table 7. Output from the AOSS was connected directly to the GemCone nebulizer inside the ICP-ES. Four wavelengths ( $\mathrm{Sc} 361.384 \mathrm{~nm}, \operatorname{Re} 197.240 \mathrm{~nm}, \operatorname{Re} 227.525 \mathrm{~nm}$ and $\operatorname{Re} 221.426 \mathrm{~nm}$ ) were measured using a maximum integration time of $20 \mathrm{sec}$ and 2-point background correction selected from both sides of the wavelength. Rhenium was used as a non-radioactive surrogate for technetium while scandium was used as an internal standard. The segmented array detector used a short pre-integration read prior to each measurement to determine individual integration times for each wavelength. Output from the sampling system could be evaluated approximately every 27 to 47 seconds, depending on the concentration of scandium.

Table 7: Plasma Conditions for ICP-ES.

\begin{tabular}{|c|c|}
\hline Instrument & PE Optima 3000 \\
\hline Power & 1400 Watts \\
\hline Plasma gas (Ar) & $15 \mathrm{~L} / \mathrm{min}$ \\
\hline Auxiliary/Coolant gas (Ar) & $0.5 \mathrm{~L} / \mathrm{min}$ \\
\hline Carrier gas (Ar) & $0.8 \mathrm{~L} / \mathrm{min}$ \\
\hline Solution flow rate & dependent on AOSS $(1.0$ \\
& mls/min) \\
\hline Spectrometer & Echelle \\
\hline
\end{tabular}

The simple program detailed previously in Table 5 was used throughout this section to evaluate the AOSS. The experimental conditions used are listed in Table 8. Initially, the analysis flow rate was set for $1.0 \mathrm{mls} / \mathrm{min}$ and the flush flow rate was set for $2.0 \mathrm{ml} / \mathrm{min}$. After trial 2, all flow rates were set at 1.0 $\mathrm{mls} / \mathrm{min}$ to maintain a constant flow rate during testing. The wash solution was spiked with scandium at various concentrations to act as an internal standard during the measurement of rhenium. The following table details sampling conditions for evaluation experiments. The system was automatically shutoff multiple times during trial 4 due to tripping of the photoelectric sensor. We believe the warnings were caused by retention of solution on the sides of the mixing chamber. The mixing chamber was then tilted slightly resulting in only one system shutoff on the subsequent trial. Simulant A spiked with Re was used as the process solution during the last trial. Initially, we used $2 \% \mathrm{HNO}_{3}$ spiked with $0.2 \mathrm{mg} / \mathrm{L} \mathrm{Sc}$ for the wash solution. This solution produced a white precipitate most likely due to aluminum, which clogged the system during the trial. Dilution of the simulant with $6 \% \mathrm{HNO}_{3}$ gave no indication of a precipitate. 
BNF-003-98-0293

June 29, 2000

Page 11 of 15

Table 8: Experimental conditions for evaluation of AOSS

\begin{tabular}{|c|c|c|c|c|c|}
\hline Test D & $\begin{array}{c}\text { Length of } \\
\text { run }\end{array}$ & $\begin{array}{c}\text { Process } \\
\text { Soln }\end{array}$ & $\begin{array}{r}\text { Fursh flow } \\
\text { rate }\end{array}$ & $\begin{array}{c}\text { Sc } \\
\text { Conc }\end{array}$ & \\
\hline 1 & $1 \mathrm{hr}$ & $10 \mathrm{ppm} \mathrm{Re}$ & $2.0 \mathrm{mls} / \mathrm{min}$ & 2.0 & \\
\hline 2 & $6 \mathrm{hr}$ & $10 \mathrm{ppm} \mathrm{Re}$ & $2.0 \mathrm{mls} / \mathrm{min}$ & 2.0 & \\
\hline 3 & $8 \mathrm{hr}$ & $10 \mathrm{ppm} \mathrm{Re}$ & $1.0 \mathrm{mls} / \mathrm{min}$ & 2.0 & \\
\hline 4 & $8 \mathrm{hr}$ & $10 \mathrm{ppm} \mathrm{Re}$ & $1.0 \mathrm{mls} / \mathrm{min}$ & 0.2 & $\begin{array}{c}\text { multiple system } \\
\text { warnings }\end{array}$ \\
\hline 5 & $8 \mathrm{hr}$ & $10 \mathrm{ppm} \mathrm{Re}$ & $1.0 \mathrm{mls} / \mathrm{min}$ & 0.2 & system warning \\
\hline 6 & $2 \mathrm{hr}$ & Simulant A & $1.0 \mathrm{mls} / \mathrm{min}$ & 0.2 & pump leak after 2 hrs \\
\hline
\end{tabular}

\section{Results and Discussion}

The first trial was setup to determine the timing for the ICP-ES connected to the AOSS. The measured output from the ICP-ES looked similar to the UV-VIS AOSS injection profile shown in Figure 8. While the injection profile resulted in a peak, there was a window of approximately 2-3 minutes at the peak midpoint where the signal was relatively steady. This is the ideal location for ICP-ES measurement. Peak midpoints were measured every 1160 seconds (19.4 minutes) with this program. The number of rinses and injections could be easily modified to achieve the desired $15 \mathrm{~min} / \mathrm{sample}$ specified by BNFL.

The next two trials were similar except for the change in flow rate. There was a large fluctuation in internal standard intensity between injection peaks for trial 2. Figure 10 illustrates the fluctuation of scandium intensity over time. The large decrease in concentration was the result of the change in flush flow rate from $2.0 \mathrm{ml} / \mathrm{min}$ to $1.0 \mathrm{ml} / \mathrm{min}$, which changed the efficiency of the nebulizer. Figure 11 illustrates the same data for trial 3 , which maintained a constant flow rate. The scandium was much steadier for trial 3 except for a few anomalous points. However, the system still maintained two sources of scandium fluctuation shown in Figure 12. First, the scandium dropped in concentration during the analysis cycle because sample was added to the wash solution, diluting the scandium concentration. This decrease was expected and resulted in a 1.12X dilution of the internal standard. Second, there was an oscillation between the measurement of scandium in the system. This oscillation was not present for the measurement of rhenium. We believe this fluctuation was due to the action of the piston pump. Because of scandium's high sensitivity, integration time was much shorter than the integration time for . rhenium. Thus, a decrease in scandium concentration would remove the oscillation. This oscillation in scandium concentration resulted in a poor internal standard correction for rhenium. The result was a 5$6 \% \mathrm{RSD}$ in the 3-point and 5-point averages for rhenium.

Trials 4 and 5 were similar to trial 3 except the scandium concentration in the wash solution was decreased from $2.0 \mathrm{mg} / \mathrm{L}$ to $0.2 \mathrm{mg} / \mathrm{L}$. The change in concentration eliminated the fluctuation in scandium intensity from measurement to measurement (see Figure 13). Due to the problems with the 
BNF-003-98-0293

June 29,2000

Page 12 of 15

photoelectric sensor,.trial 4 did not give enough data to evaluate precision. However, Trial 5 gave good precision for the two primary Re wavelengths: Re $197.240 \mathrm{~nm}$ and $\operatorname{Re} 227.525 \mathrm{~nm}$. Figure 14 and Figure 15 illustrate the good precision of the AOSS coupled to the ICP-ES. The peaks were reproducible without the oscillation found with higher scandium concentrations. The data for the 3point averages for these Re wavelengths is tabulated below in Table 9. The \%RSD for $\operatorname{Re} 197.2 \mathrm{~nm}$ was $1.7 \%$ and for $\operatorname{Re} 227.5 \mathrm{~nm}$ was $2.1 \%$.

Table 9: 3-point average intensities for $\operatorname{Re} 197.2 \mathrm{~nm}$ and $227.5 \mathrm{~nm}$.

\begin{tabular}{|c|c|c|}
\hline Sample D & $\begin{array}{r}\text { Re 197.24 nm } \\
\text { (cps) }\end{array}$ & $\begin{array}{c}\text { Re 22 } \\
\text { (cps) }\end{array}$ \\
\hline 1 & 11.49 & 32.88 \\
\hline 2 & 11.66 & 33.56 \\
\hline 3 & 11.84 & 34.12 \\
\hline 4 & 11.41 & 32.76 \\
\hline 5 & 11.74 & 33.67 \\
\hline 6 & 11.53 & 33.26 \\
\hline 7 & 11.36 & 32.56 \\
\hline 8 & 11.27 & 32.23 \\
\hline 9 & 11.27 & 32.20 \\
\hline 10 & 11.53 & 33.06 \\
\hline 11 & 11.65 & 33.26 \\
\hline 12 & 11.71 & 33.33 \\
\hline 13 & 11.41 & 32.45 \\
\hline 14 & 11.40 & 32.64 \\
\hline 15 & 11.35 & 32.02 \\
\hline 16 & 10.98 & 31.04 \\
\hline 17 & 11.55 & 32.61 \\
\hline 18 & 11.36 & 32.17 \\
\hline 19 & 11.61 & 32.87 \\
\hline 20 & 11.49 & 32.68 \\
\hline & & \\
\hline Avg & $\mathbf{1 1 . 4 8}$ & $\mathbf{3 2 . 7 7}$ \\
\hline Std Dev & $\mathbf{0 . 1 9 7}$ & $\mathbf{0 . 6 8 4}$ \\
\hline \%RSD & $\mathbf{1 . 7 1}$ & $\mathbf{2 . 0 9}$ \\
\hline & & \\
\hline
\end{tabular}

For the last phase of AOSS evaluation, we used simulated envelope A spiked with $10 \mathrm{ppm}$ Re for the process solution. Initially, $2 \% \mathrm{HNO}_{3}$ was used for the wash/diluant solution. Some of envelope $\mathrm{A}$ precipitated on contact with the $2 \% \mathrm{HNO}_{3}$ diluant solution. This precipitation caused the AOSS pumps to clog, discontinuing rhenium monitoring. The trial was restarted after cleaning the pump and substituting $6 \% \mathrm{HNO}_{3}$ for the diluant solution. No precipitation was evident with new diluant; however, the pumps began to leak after two hours. Figure 16 shows the data collected during this trial. The peaks in this figure were not as consistent as trial 5 , but were reasonable for the salt solution. There was not 
BNF-003-98-0293

June 29, 2000

Page 13 of 15

enough data to evaluate precision due to the leaking pumps, but there were no problems evident with the collected data.

Overall, the sampling system worked well coupled to the ICP-ES. Relative precision was approximately $2 \%$ over 8 hours for $10 \mathrm{mg} / \mathrm{L}$ Re solutions. Precision was degraded slightly in switching to envelope $\mathrm{A}$ spiked with Re. There were also several areas of concern in using the sampling system. First, the sampling system flow rate did affect the efficiency of the nebulizer; however, all measurements will be made during the analysis sequence for the on-line analyzer. Second, the concentration of the internal standard was critical. If the concentration were too high, the signal would oscillate due to the piston pumps. If the concentration were too low, the signal would be buried in the plasma background. For the Optima 3000 , the ideal scandium concentration was between $0.5-0.2 \mathrm{mg} / \mathrm{L}$. Third, the concentration of acid for sample dilution was also critical. Dilution with $2 \% \mathrm{HNO}_{3}$ did not lower the $\mathrm{pH}$ enough to prevent the Al from precipitating. 
BNF-003-98-0293

June 29, 2000

Page 14 of 15

\section{Figure Captions}

Figure 1: Picture of both components of the AOSS.

Figure 2: Schematic of AOSS.

Figure 3: Picture of wet component: pumps, valves, tubing, etc.

Figure 4: Schematic of wet. component.

Figure 5: Picture of mixing chamber.

Figure 6: Picture of controlling component.

Figure 7: Schematic of controlling component.

Figure 8: Sample profile using Spectronic 20.

Figure 9: 12 hour run.

Figure 10: Scandium intensity during trial 2 measured by ICP-ES. The large fluctuation is due to changing rinse/analyte flow rates at the AOSS.

Figure 11: Scandium intensity during trial 3 measured by ICP-ES. Except for a few anomalous points, the fluctuation has been greatly reduced.

Figure 12: Scandium intensity for the first 1.5 hours of trial 3.

Figure 13: Scandium intensity during trial 5 measured by ICP-ES. Oscillation caused by the pumps has been removed.

Figure 14: ICP-ES Output intensity for Re during trial 5. The ICP-ES took a measurement every 47 seconds. The large gap was due to a photoelectric sensor error.

Figure 15: Snapshot of Re output taken from Figure 14. The AOSS-ICPES combination produced reproducible peak shapes and intensities for $\mathrm{Re}$ when using $\mathrm{Sc}$ as an internal standard.

Figure 16: Rhenium intensity from trial 6 using envelope $A$ for the process solution. 
BNF-003-98-0293

June 29, 2000

Page 15 of 15

\section{Tables}

Table 1: Cycle types in the sampler control program editor.

Table 2: Example of a simple sampler control program.

Table 3: Example of a more complex sampler control program.

Table 4: Sample injection profile parameters.

Table 5: Sample injection profile sampler control program.

Table 6: Sample injection profile parameters for 12 hour run.

Table 7: Plasma Conditions for ICP-ES.

Table 8: ICP-ES experimental conditions for evaluation of AOSS.

Table 9: 3-point average intensities for $\operatorname{Re} 197.2 \mathrm{~nm}$ and $227.5 \mathrm{~nm}$.

\section{References}

1. Sobejana, A. F., Jr., . SP-W375PT-IN-00001 REV.C "TWRS-Privatization Technetium MonitoringMeasurement Specification" (1999).

2. Russell Eibling, internal communication on simulant formulations. 


\section{Figure 1}

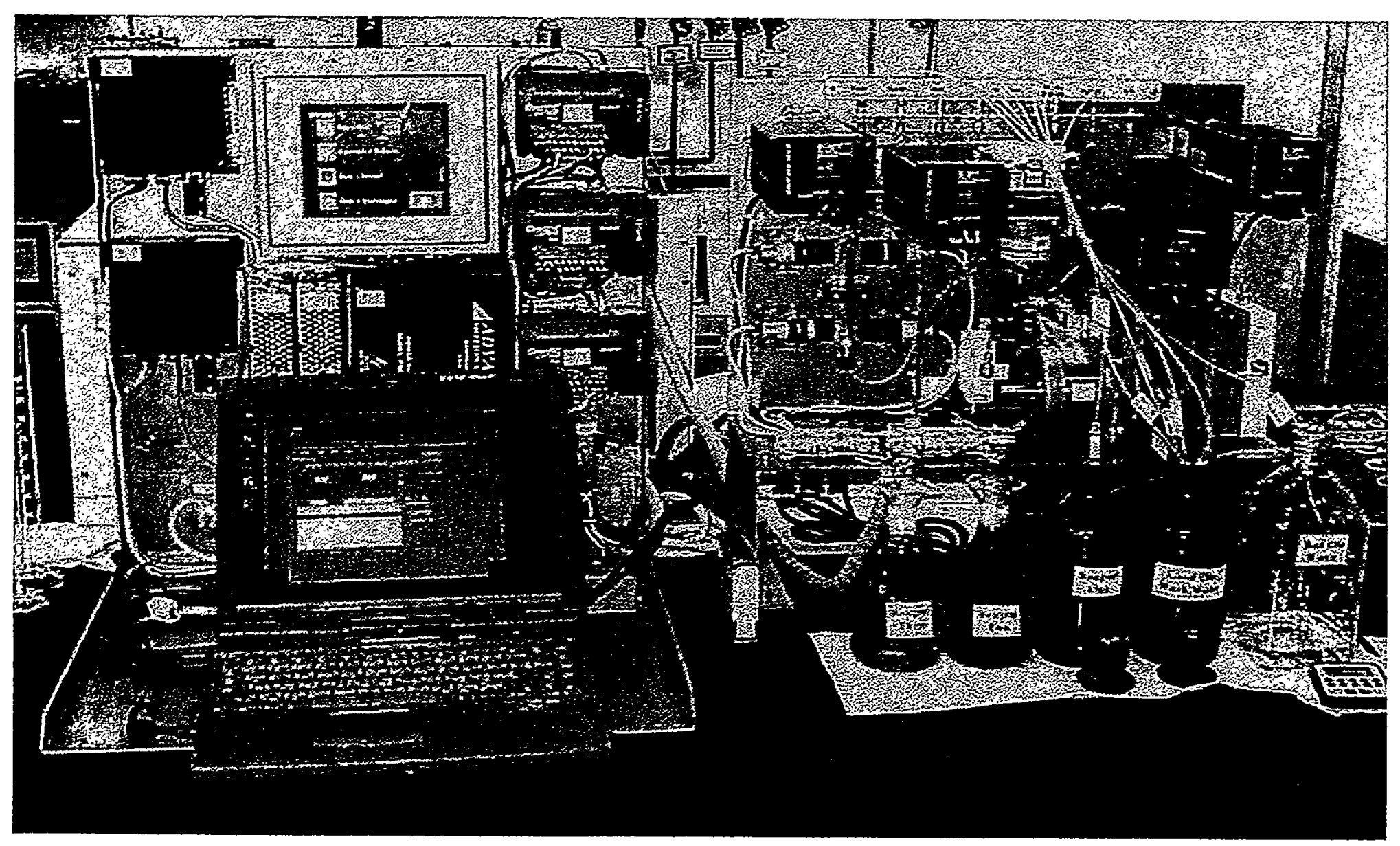




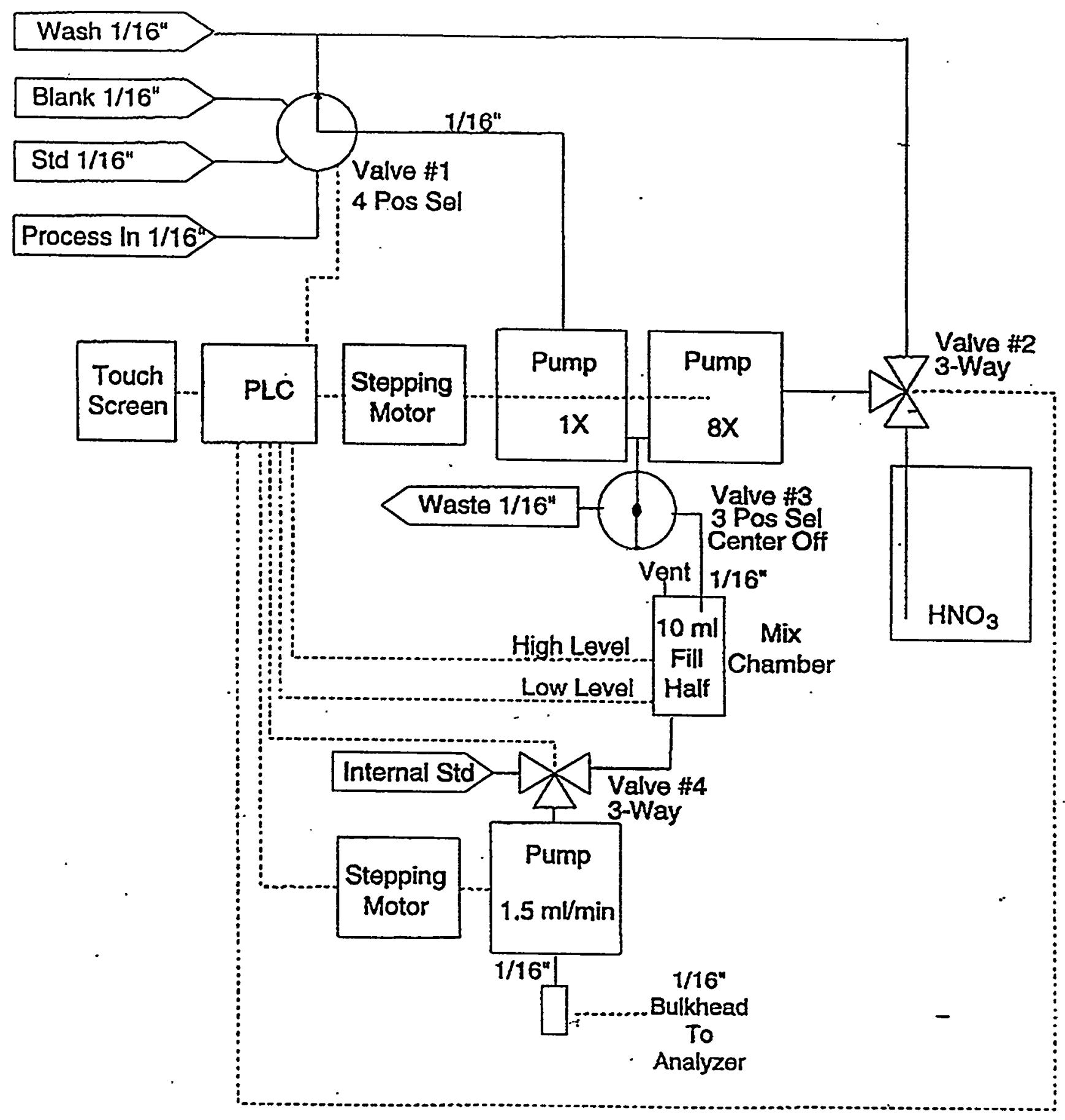

Drawting 100200-3 Scalo None Date 07/22/99 \begin{tabular}{l|l|l|l}
\hline her * A1 & Oram by RP & Rev by RP & Dato 08/24/99
\end{tabular} TrRe: Pump Difuter, Analyzer Prep, Flow Sheot 
Figure 3

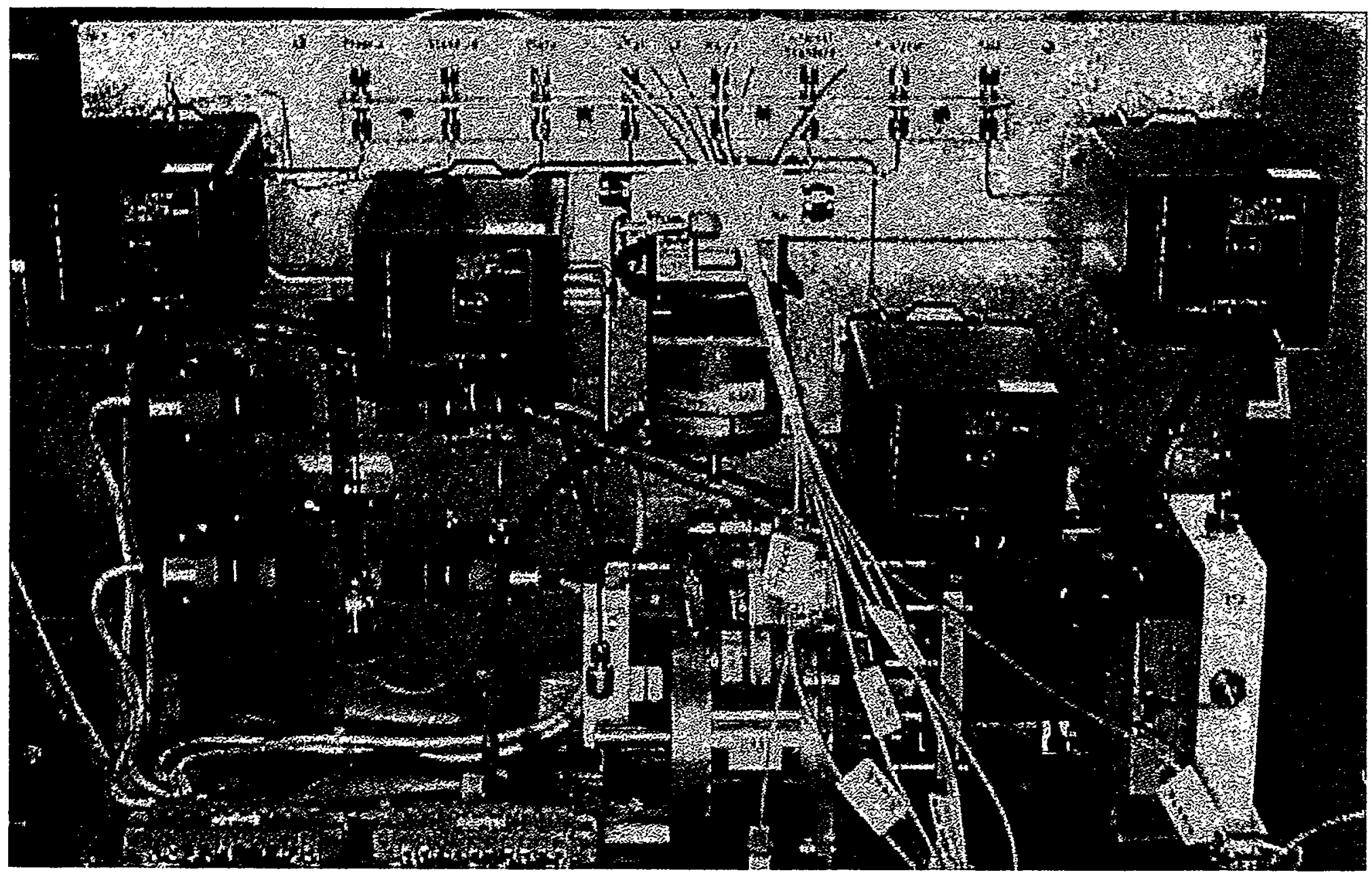




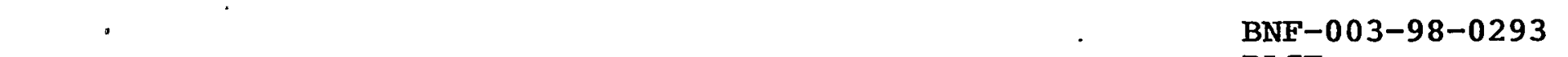

Figure 4

PAGE $/ 9$

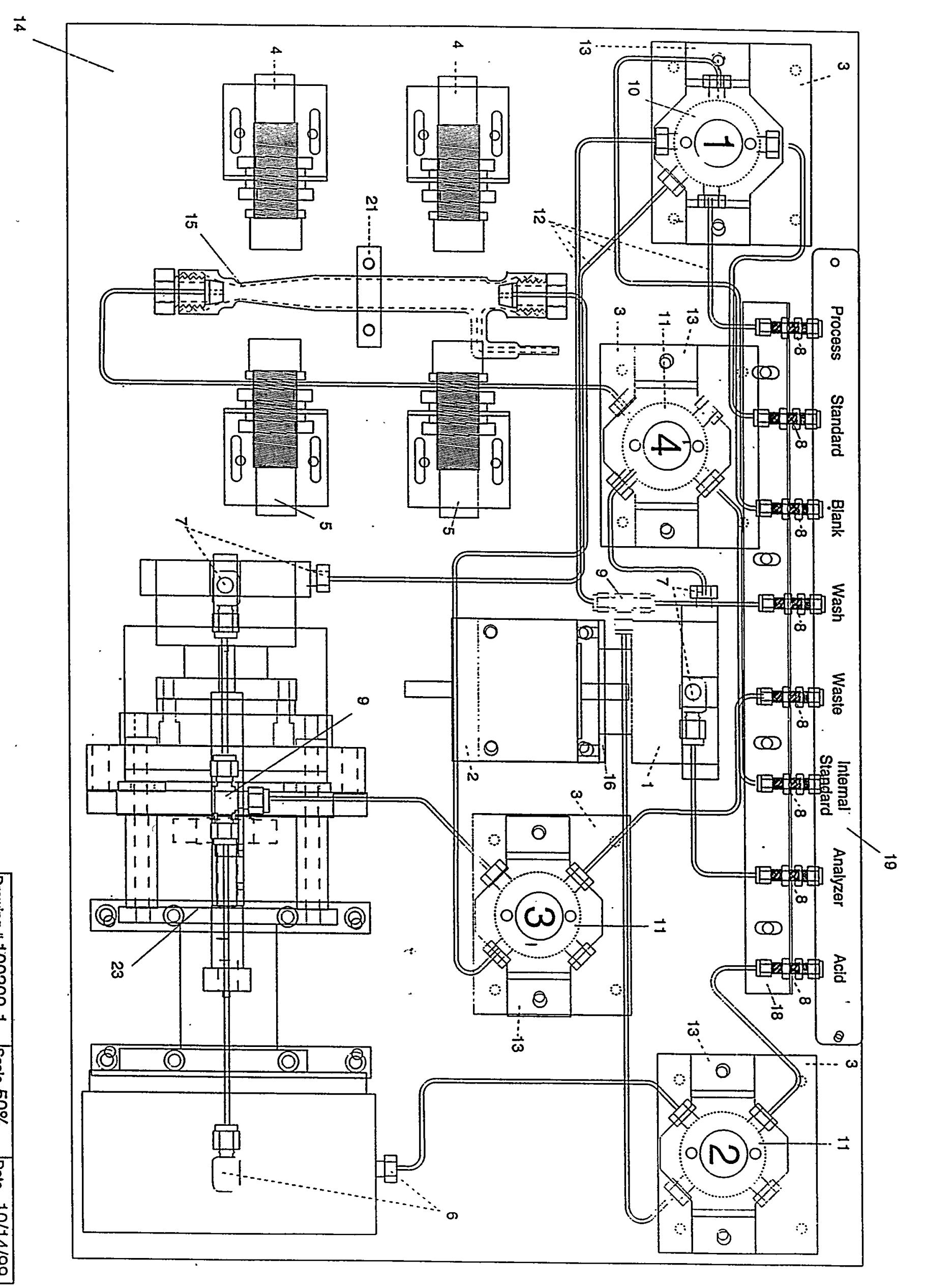




\section{Figure 5}

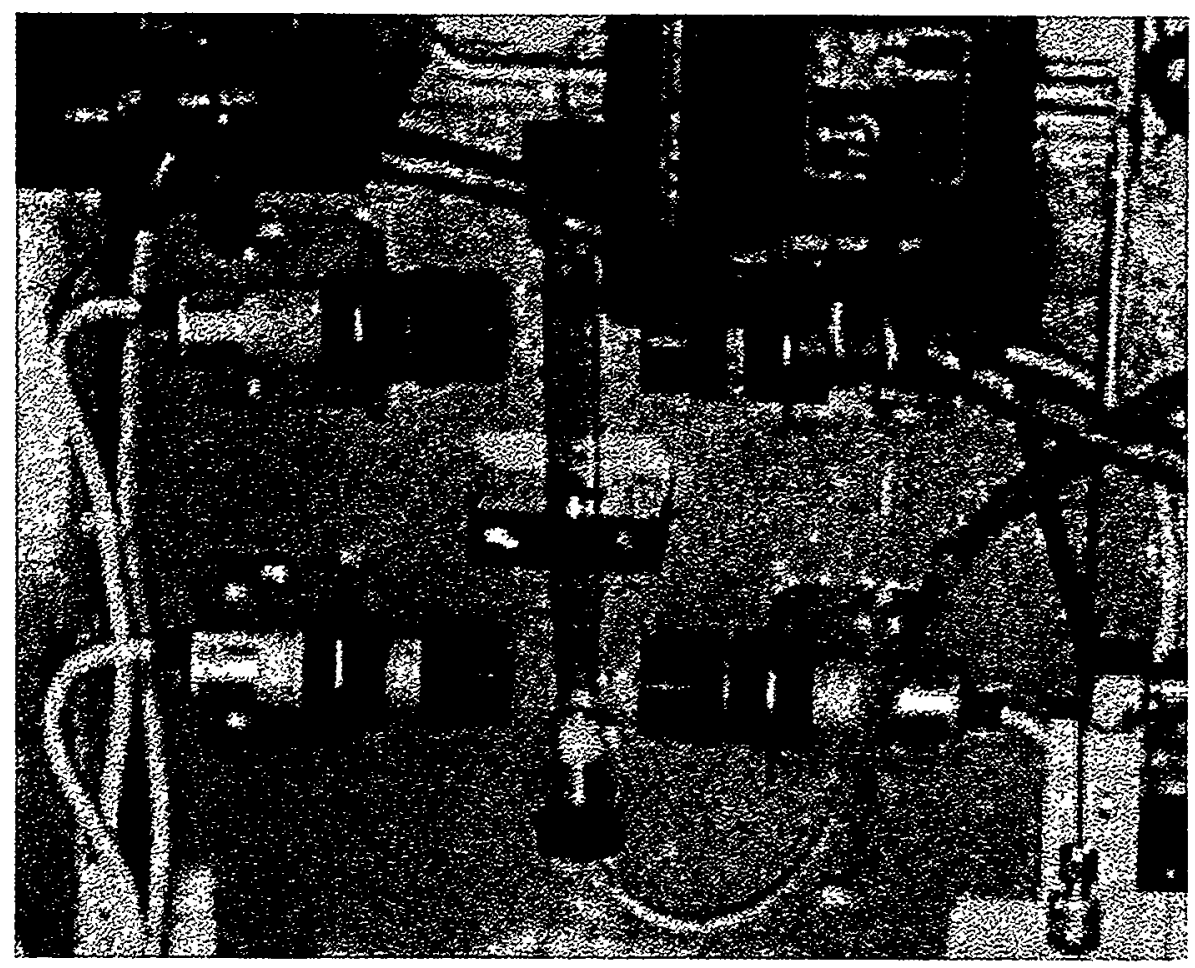




\section{Figure 6}

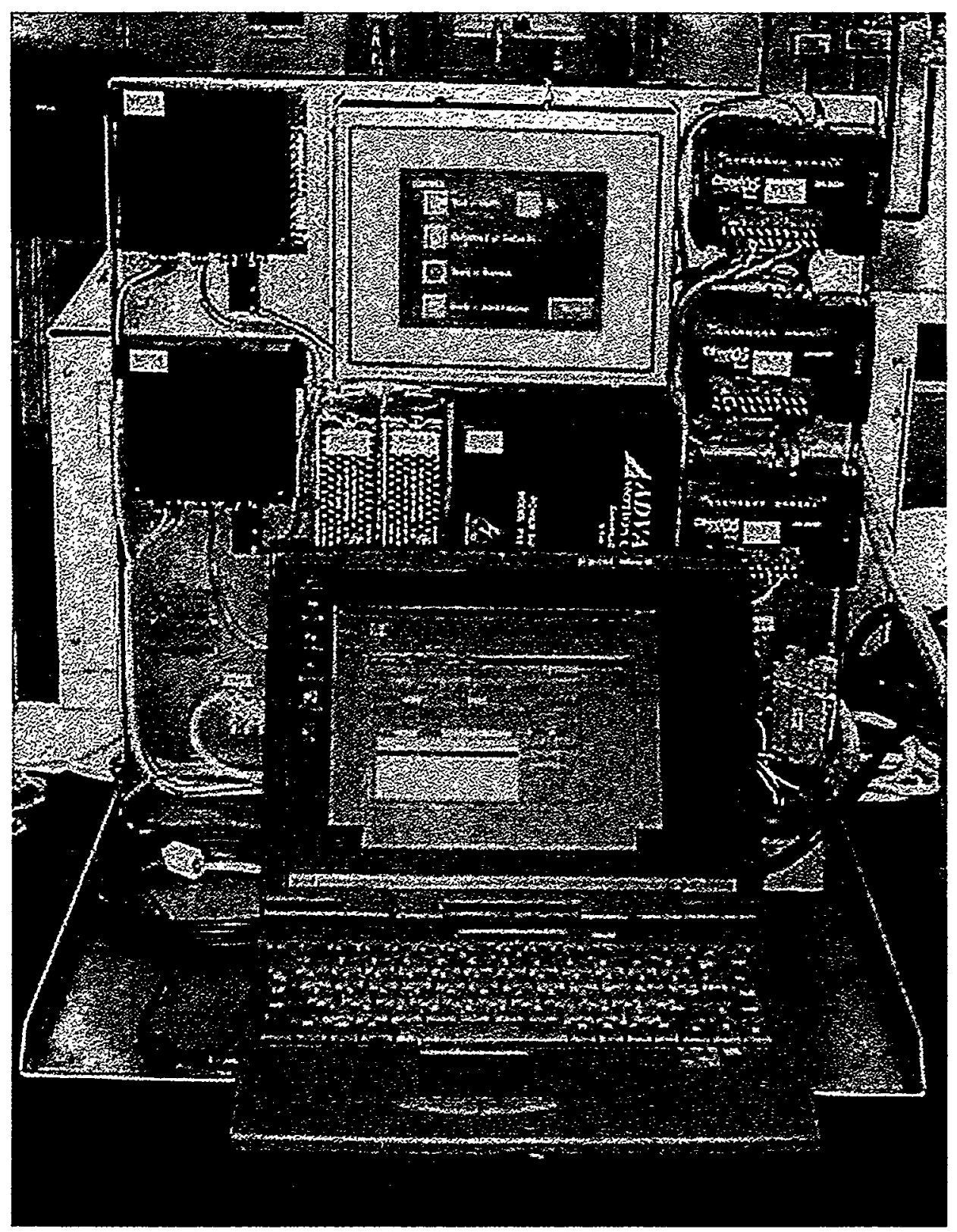




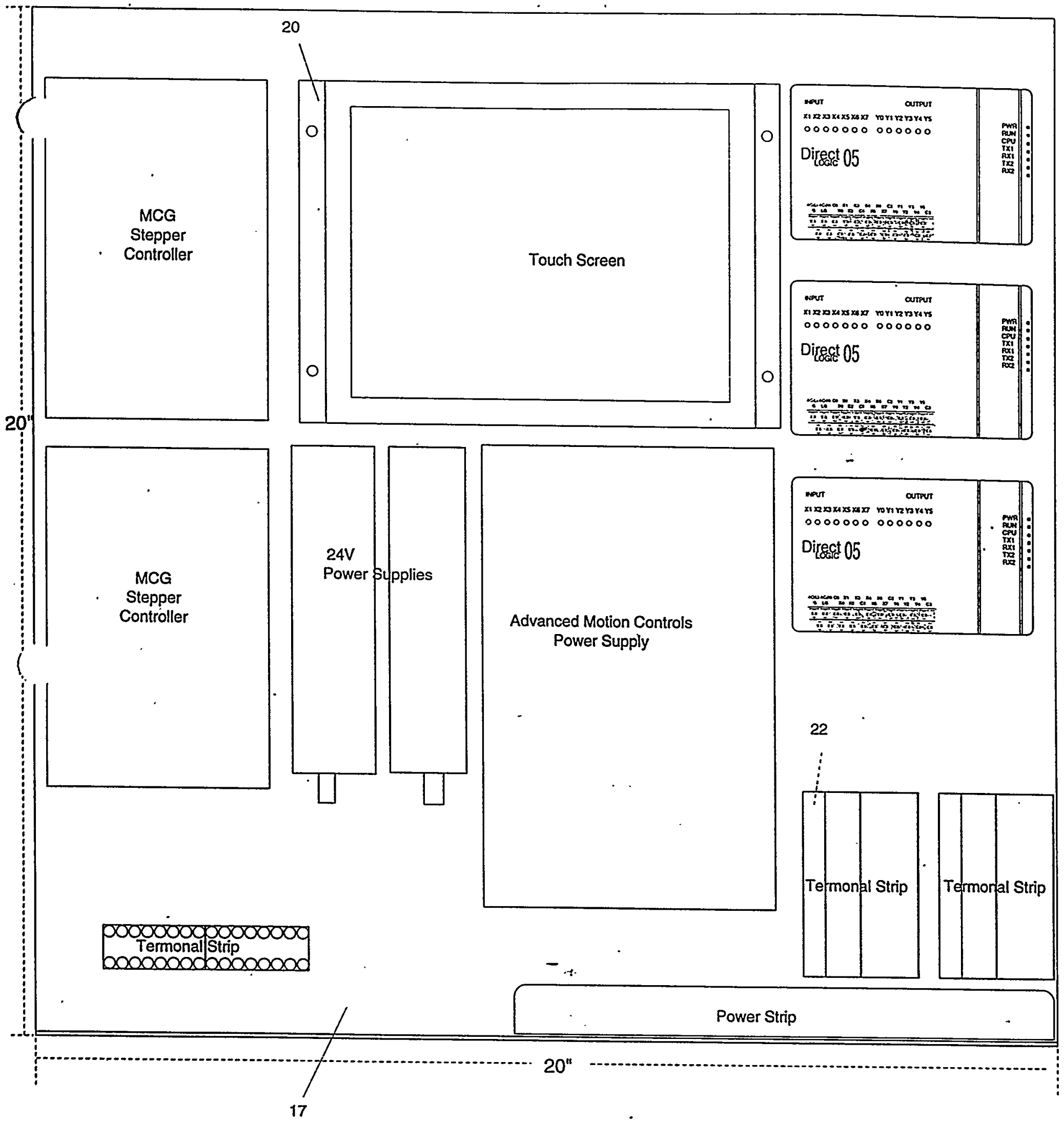

\begin{tabular}{|l|l|ll|}
\hline Drawing \# 100200-2 & Scale 40\% & Date & $07 / 22 / 99$ \\
\hline
\end{tabular} \begin{tabular}{|l|l|l|l|}
\hline Rev \# R4 & Drawn by RP & Rev by RP & Date 09/23/99 \\
\hline
\end{tabular} TiTLE: Pump Diluter, Analyzer Prep, Control Panel Page 2 

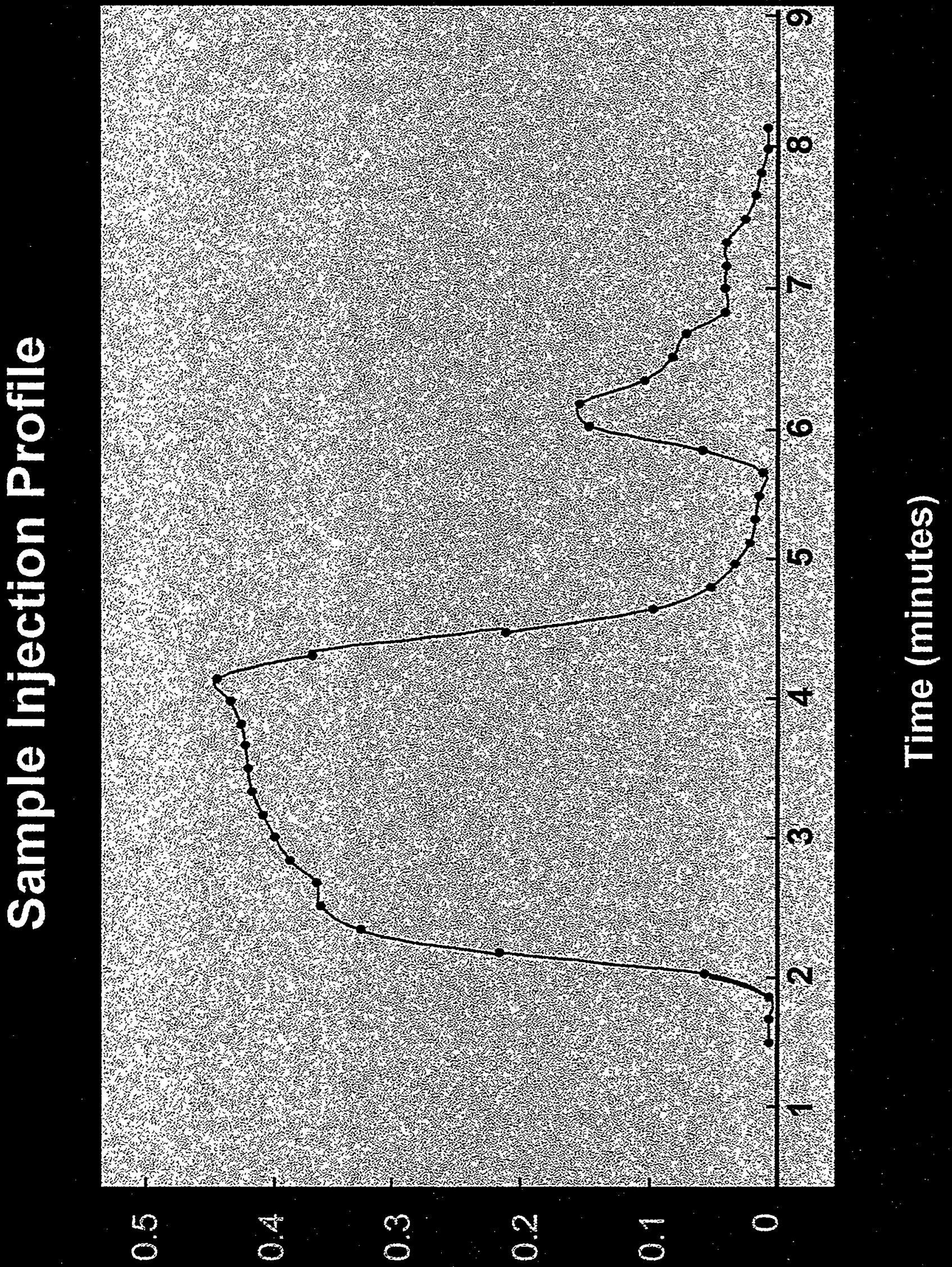


\section{Figure 9}

BNF-003-98-0293

PAGE 24

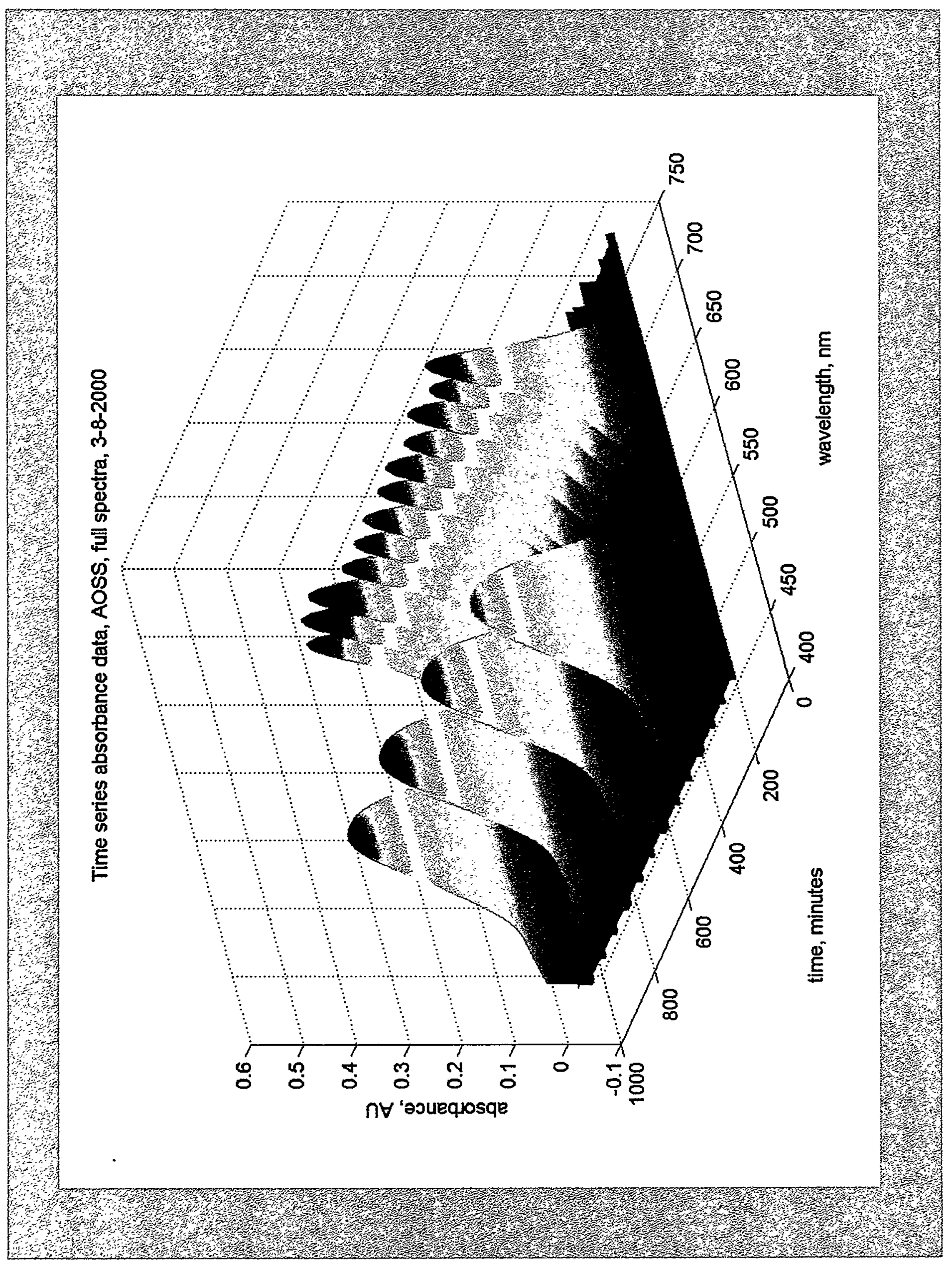




\section{Figure 10}

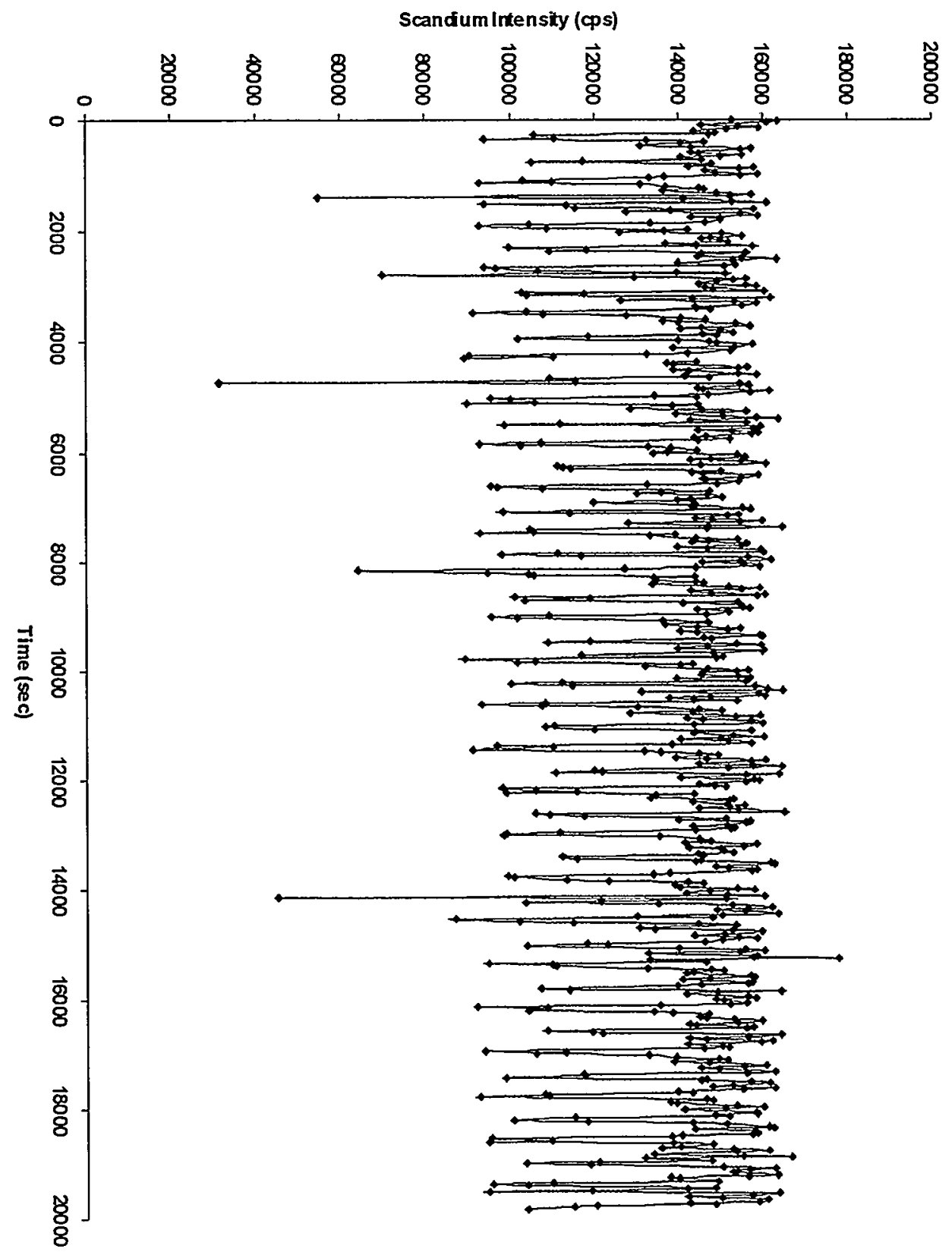


BNF-003-98-0293

PAGE 26

\section{Figure 11}

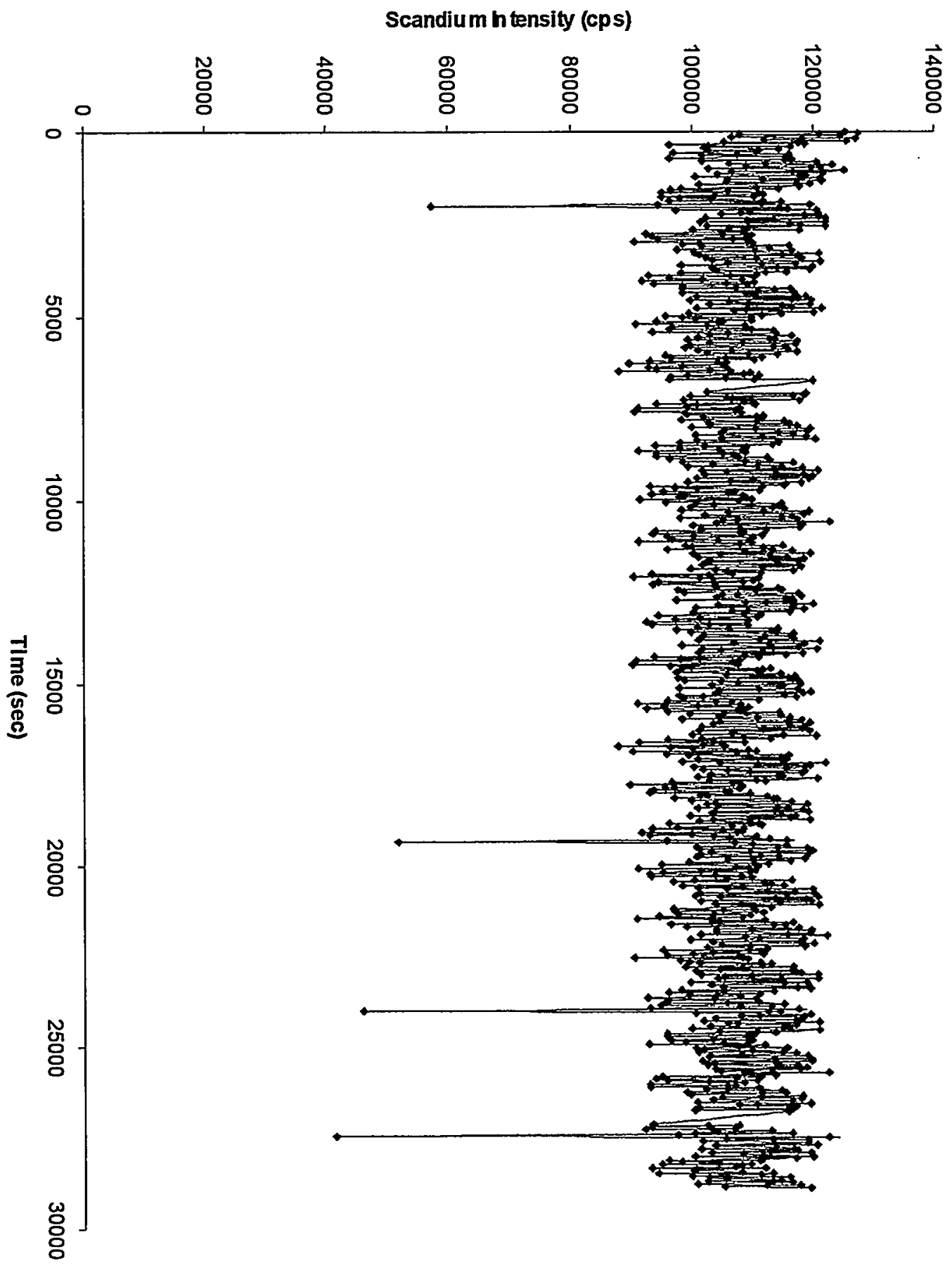




\section{Figure 12}

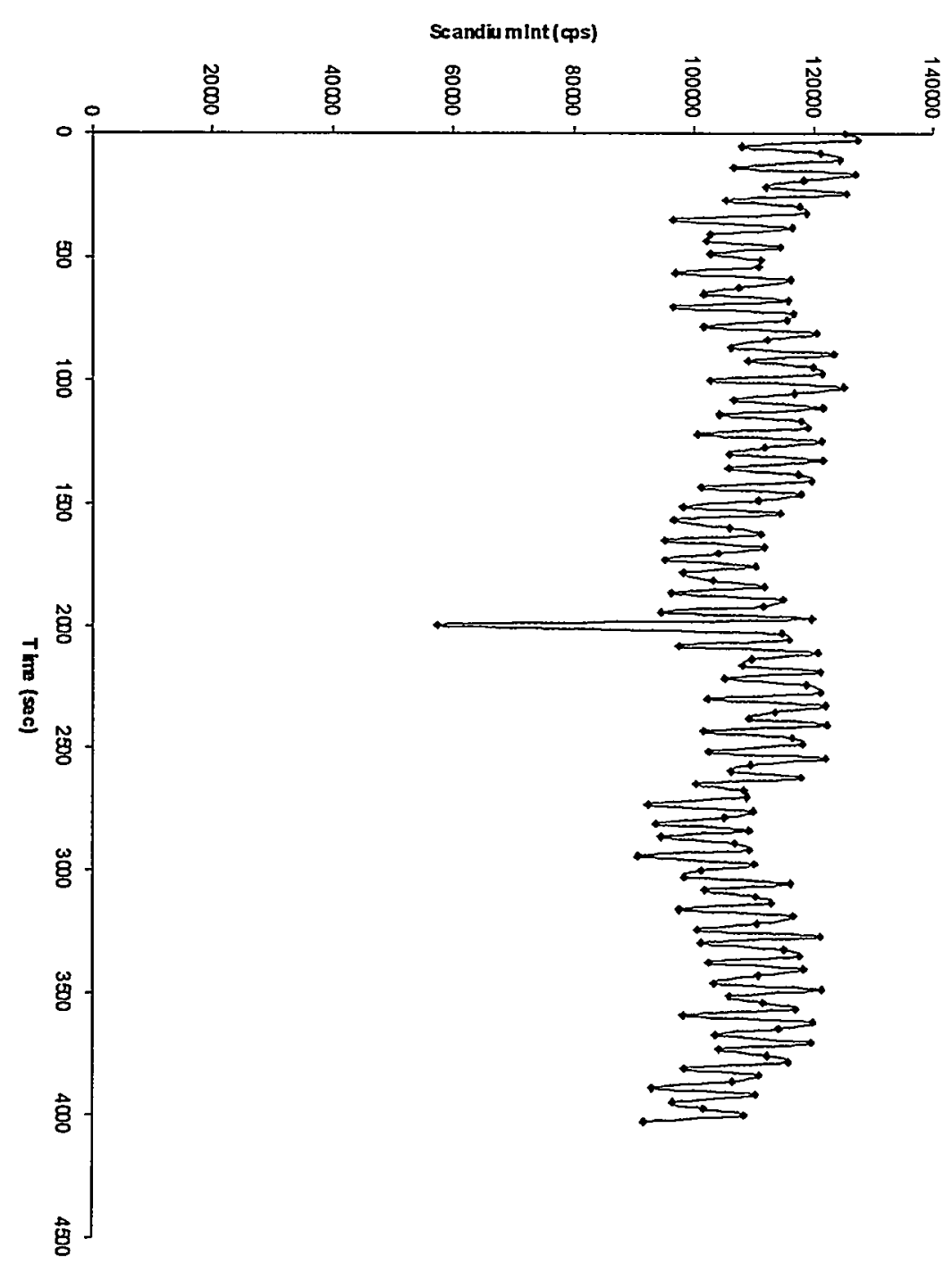




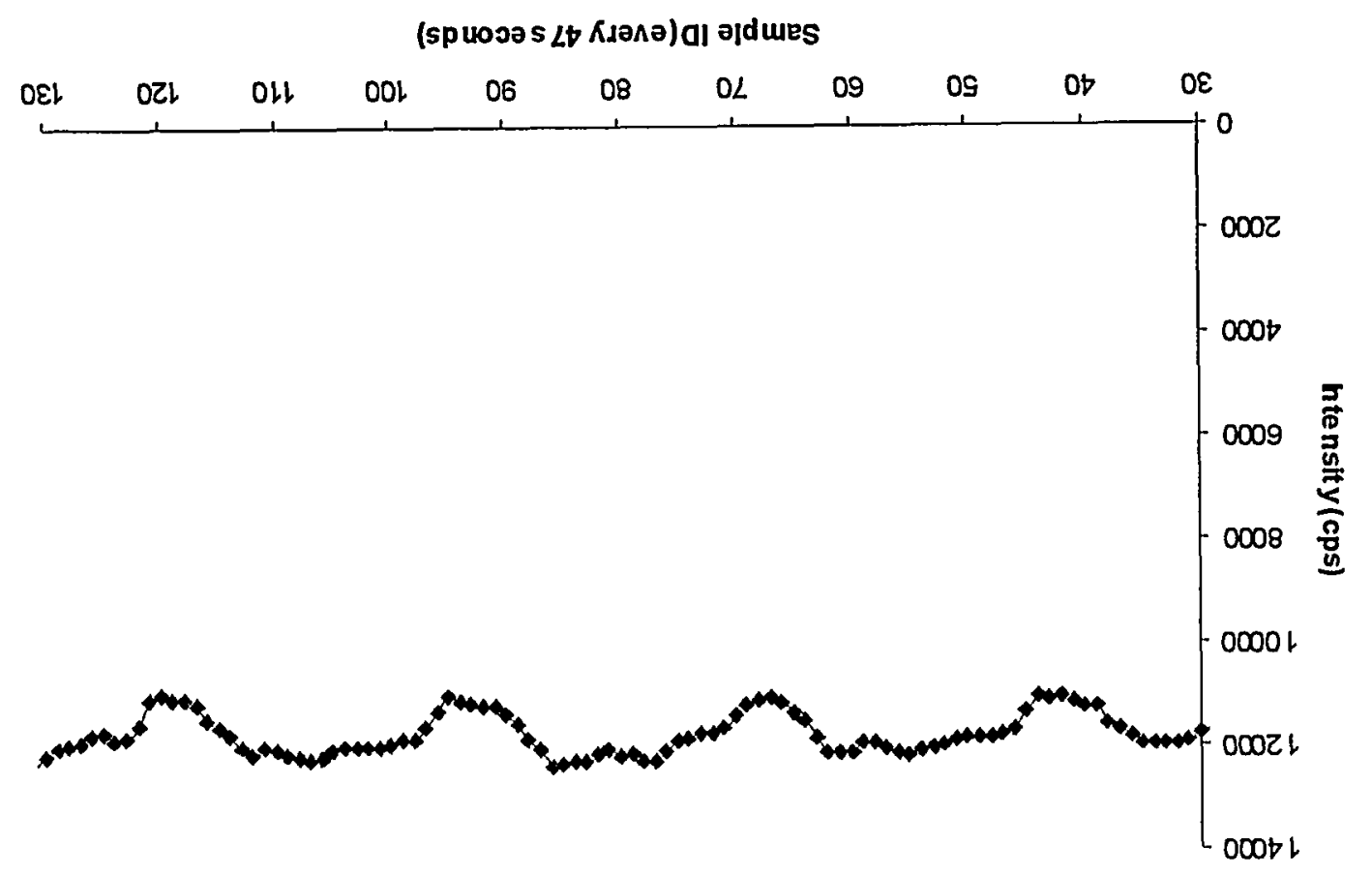

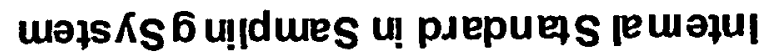




\section{Figure 14}

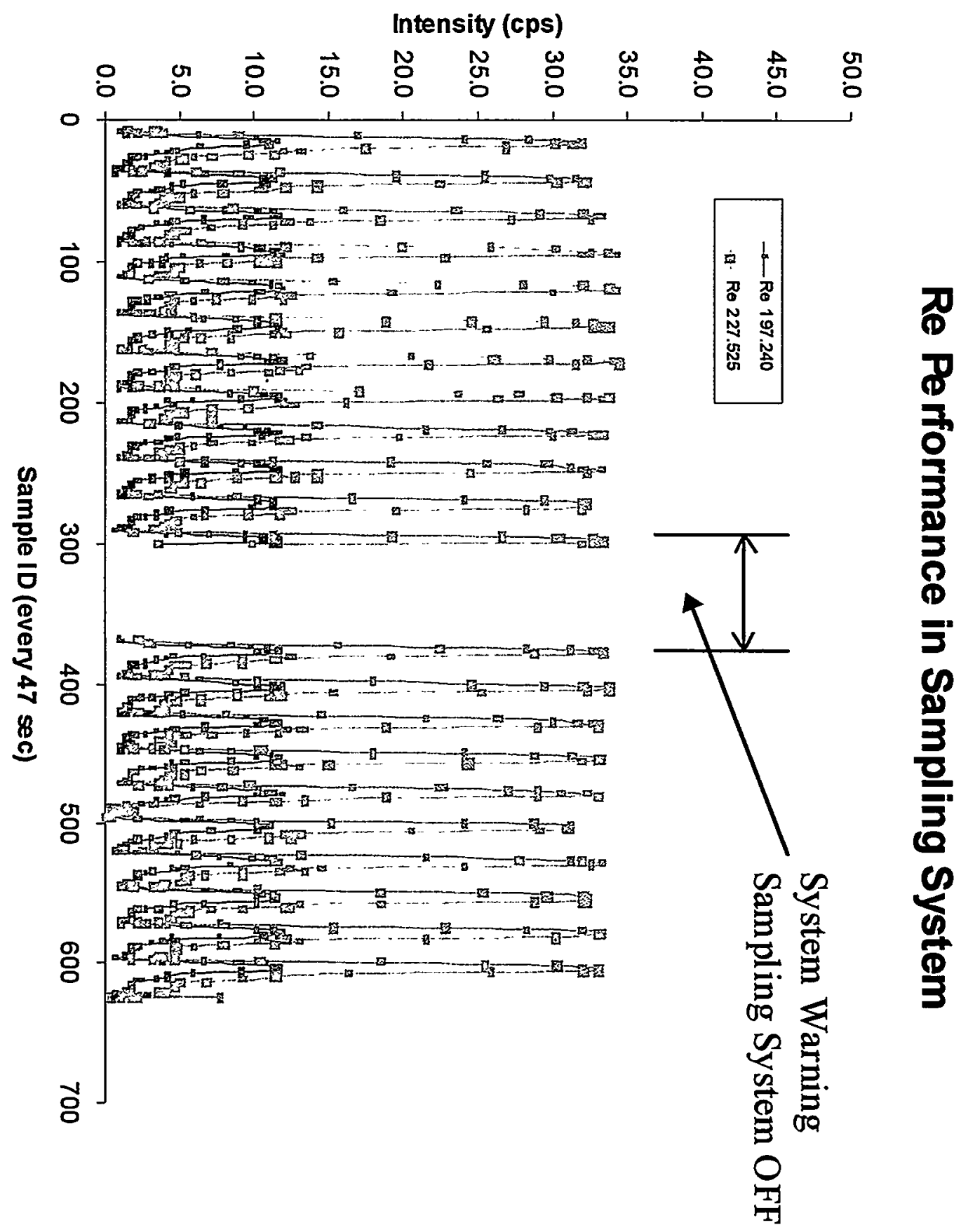


Figure 15

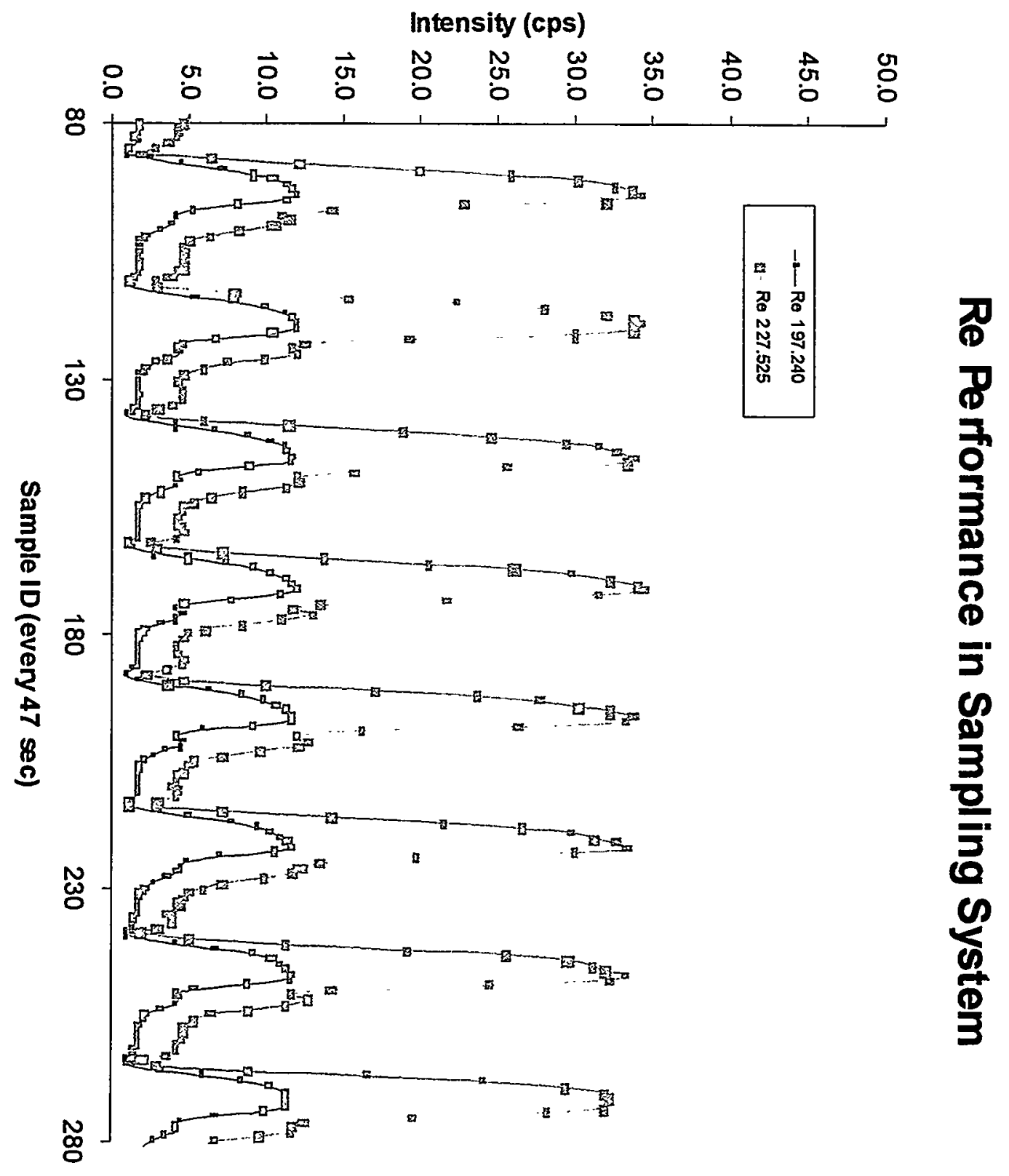


Figure 16

PAGE 31

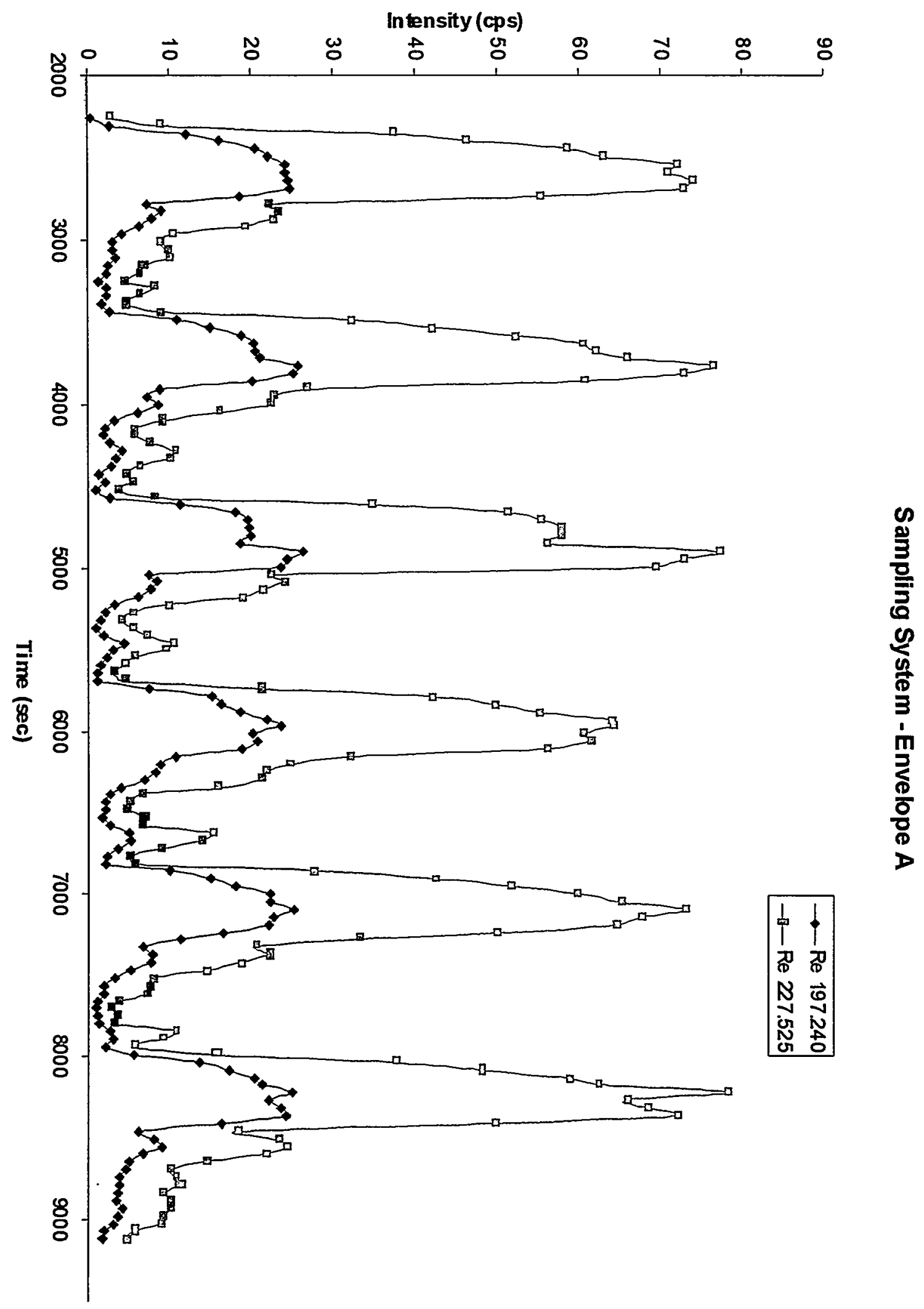

